\title{
The Protection and Inheritance of Minority Culture under Multi-culture Background
}

\author{
For minority preparatory education
}

\author{
Yali Teng \\ Minzu School \\ Huanghe Science and Technology College \\ Zhengzhou, China
}

\begin{abstract}
Preparatory education for minorities is a special level of higher education, an important way to cultivate minority talents and a significant measure to drive the development of politics, economy and culture in minority regions. In addition, as a unified multinational country, China, under the multi-language and multi-letter background, determines the diversity of national culture. And due to different geographies, social structures and humanistic environment, each nation has formed its own unique culture; hence, when carrying out multiple cultures in the culture education of minority students at preparatory stage, we must first follow Chinese national spiritual homeland.
\end{abstract}

Keywords-multi-culture; national culture; protection; inheritance

\section{INTRODUCTION}

The culture system of Chinese nation is integrated with 56 national culture systems, which is unified in diversity but with commonness and individualities through a long-term contacts, co- habitation and confluence of all nations. Therefore, while educating minority students at preparatory stage, we effectively lead them to treat dominant culture and national culture in a proper way, improve their ability of culture selection and culture consciousness as well as cast off either-or thought of selection. In this article, the writer, combining with own education experiences of preparatory education on minority students for nearly ten years, discusses how to protect and inherit minority culture under the background of multiple culture.

\section{PARTICULARITY OF NATIONAL PREPARATORY STAGE}

In the Regulations on Minority Preparatory Class and Nation Class of Regular Institutions of Higher Education, the Ministry of Education points out that, national preparatory class refers to a form of running a school carrying out preparatory education of university or college (higher vocational) education on the minority students who took National Higher Education Entrance Examination of current year, enjoyed proper score reduction policy and were admitted the best examinee. The purpose of preparatory education is to strengthen students' moral quality-oriented education and cultural basic knowledge and skills so that they will get further all-round development of morality, intelligence, physique and aesthetic and lay them a good foundation to enter university or college (higher vocation).

Hence, preparatory education for minorities is a special level of higher education, an important way to cultivate minority talents and a significant measure to drive the development of politics, economy and culture in minority regions. However, as for minority preparatory students, there two transitions in the face of them: their school performance comes the first, due to the preferential policy of minority nationality at college entrance exam, to certain degree, they have lower learning foundation than students who are regularly enrolled; therefore, they should improve their performances within one or two years for regular study in university and college. Secondly, culture transition. It is a task of great concern at preparatory stage, including grasp of mandarin, adaptation of outback life custom and thought on the Huaxia culture and Chinese civilization, especially for students (Xinjiang ethnic minority student as well as students studying in Korean in Northeastern regions and studying in Mongolian in Mongo.) studying in national languages at senior high school, culture transition appears particularly important and hard. In this article, it discusses the protection and inheritance of minority culture aiming at the difficulty of cultural transition in the face of minority students at national preparatory stage.

\section{Culture CiRCUMSTANCES OF STUDENTS OF MinORITY NATIONALITIES AT PREPARATORY STAGE}

Every minority preparatory student exists as a carrier of the culture of its nation, and they embody the cultural factors of morality, knowledge, mentality and folk custom of their nations. The influence of their nations is in their knowledge system, moral system and behavior system everywhere; however, learning at national preparatory stage, makes them have to face a new cultural system, the dominant culture system which makes them become the receiver of dominant culture although they comes from the minority nation, and on one hand they look forward to the dominant culture while on the other hand they lose their heads facing the new environment. In this context, they migrate between the dominant culture and national culture as a third party, hardly noticing that they has become the link man of minority culture 
and dominant culture as well as the carrier of multi-culture, which makes them embarrassed.

In the context, the dominant cultural system refers to the tremendous and multiple culture system formed by Chinese people in the long history, the endless spiritual source of Chinese people, which is jointly created by Chinese people of all nationalities and generalized and formed by Chinese people getting along with the nature. In addition, it permeates the harmony and confliction between man and nature, includes the hardships and strategies of subsistence and congeals the intelligence and brave of Chinese people. It is extensive and profound of long standing.

Nevertheless, due to the influence of region, economy and culture, most minority preparatory students, in face of dominant culture, are often in aphasiac status (particularly in economically backward monitory national regions) and seem timid in new cultural environment. The degree of strangeness is closely related to the economical and cultural development degree in the origin of student. In addition, due to the geographic restrictions and the social closure of history, the minority nations barely have communication of material and cultural information, resulting in their cultures are less influenced by the modern culture; with the addition of relatively backward development of the productive force, it severely restricts the development of economy and culture in these regions. One the contrary, the higher development degree of economy and culture in the origin of student, the more complete contact of the minority national culture and dominant culture as well as the more familiar the minority students are with the dominant culture; hence, they will accomplish learning with ease and their aphasiac degree will be relatively lower; conversely, students of minority nationalities know less dominant culture, and even most students are their first time leaving hometown and know little basic mandarin, so that they will lose their heads at preparatory stage and have a high aphasiac degree.

The above conditions embody a centralized reflection of the confliction of cultural selection and "cultural selfconsciousness". These minority preparatory students have certain capacity of independent thinking and judgment, therefore, they have large right of cultural choice that they can fully play their initiative to accept or reject various cultures in face of multiple cultures; meanwhile, these minority students at preparatory stage have low cultural self-consciousness, not fully understanding the dominant culture and the other nations' as well as having only hazy notion of the origin, forming process, characteristics, developing direction and strengths of their own nation; hence, they can neither effectively dispose the relationship among various cultures nor manage to "discarding the dross while assimilating the essence"; instead, they are full of anxiety, confusion and perplexity surrounded by all kinds of cultures. And thus phenomenon is more obvious in national preparatory students in the interchange regions of various cultures. In conclusion, the cultural environment of national preparatory students is very embarrassed and thus embarrassed stage is impenetrable, especially some good national cultures are lost gradually due to the fact that currently many traditional cultures and educations of minority nations are impacted by the dominant education of modern society, also, the younger generation knows little of national traditional culture, lacks of a sense of national identity, much less the sense of national pride. Therefore, the cultural education at national preparatory stage appears more important, and we believe that preparatory education should pay more attention on the excellent cultures of all minority nations and carry out more multi-culture educations of all nations on the national preparatory students under the premise of sticking to the spiritual homeland of Chinese people.

\section{PROTECTION AND INHERITANCE OF MULTI-NATIONAL CUlture AND MinORITY NATIONAL CULTURE}

\section{A. Origin of Multi-Culture Education: the Culture System of Chinese Nation Is A Multi-National One}

China is a unified multi-national country. Due to the conditions of multi-nation, multi-language and multi-literature, it decides the diversity of national culture; meanwhile, due to different geographies, social structures and human environments, every nation forms their unique cultures which are correlated and distinguished among different nations. From the Mongolian wrestling to Miao's dance, from the Tibetan celestial burial to hanging coffin, from the Dongba Scripture of the Naxi to Manas Epic of Khalkhas, although they are in different forms, they jointly inherit the age-old culture and records the progressive footprint of their own nation. Fundamentally, there will be no highly-developed dominant culture without the absorption and digestion of numerous minority nations' excellent cultures.

At the same time, due to closure of national regions, it, on one hand, results in economic and cultural backward of the region; on the contrary, it remains the relative completeness of the traditional culture in that region. Therefore, the national preparatory students from remote areas possess extremely excellent cultural treasure per se, so that correct guiding the students and strengthening their sense of identity of their own nation are required as well as strengthening their sense of identity and pride of Chinese nation. Only every nation maintains and rectifies the cultures created and accumulated by themselves in their development can develop the culture with their own national features. This is exact we should let students know, make them lay down the mental load, fully display their own national cultures while learning dominant culture and enrich the connotation of dominant culture with their own national cultures.

In conclusion, the culture system of Chinese nation, which is integrated with 56 national culture systems, is one unified in diversity but with commonness and individualities through a long-term contacts, co- habitation and confluence of all nations. Therefore, the cultural education of minority preparatory students must be a multi-culture education with the premise of sticking to the spiritual homeland of Chinese nation. While educating on minority students at preparatory stage, we should effectively lead them to treat dominant culture and national culture in a proper way, improve their ability of culture selection and culture consciousness as well as cast off either-or thought of selection. 


\section{B. Measures of Multi-Culture Education on Students of Minority Nationalities at Preparatory Stage}

The multi-culture features of the culture system of Chinese people decide that the minority national preparatory students in China must conduct multi-culture education under the premise of sticking to the spiritual homeland of Chinese People. Multiculture education generally refers to the education in multinational country carried out for persons who have multiple national cultures, especially the children of minority and immigrant people are available for equal educational opportunity as well as make their unique national culture and characteristics be well respected. It emphasizes that the objectives of multi-culture education not only refer to minority and immigrant, but also include the teenagers of dominant society and all students. In this article, it only aims at the multi-culture education on minority national students. Generally, national preparatory education conducts at preparatory base; hence the objectives of multi-culture education at national preparatory stage are lots of minorities all over the country instead of one or two minorities, for example, the minority national preparatory students of Huanghe Science and Technology College of the year 2008 are from 17 regions and compose of 45 nations. Thus, the multi-culture education will face a great challenge, so that we must make overall plans and take all factors into consideration and play favorites on no account. For this purpose, we take lots of measures mainly in aspects of course content, student level and teacher quality.

First of all, cultural differences between different nations, including the traditions, customs, spirit, mentality and emotions formed through historical accumulation of each nation for long term, must be taken into consideration when selecting course contents. And these are nether only simple accumulation or knocking-together of national cultures nor explanation and interruption of knowledge related to each nation, instead, these are the collision, integration and communication among different national cultures and a conversion from self-satisfaction and conservatism to complete harmony. It is our task to, instead of teaching them endless cultural knowledge points, make the students grasp the profound national culture, feel the tremendous strength of long standing, understand the connotation of the national culture and make them know that Chinese nation is one of great, of colorful and it has a tremendous cohesion.

In regard to class contents, we must emphasize language teaching. Due to the fact that language generally is an obstacle in cultural education on lots of preparatory students, language barrier is particularly prominent. At the same time of teaching in Han language, the relevant language level of minority students should be taken into consideration, because different languages mean different ways of thought and communication. Of which, it contains different cultural connotations, so that in new language environment, the students have to face the confliction of new and old culture environment and establish new value and ways of thoughts. And thus, as for minority students know little dominant culture, it increases the difficulty for them to cognize; if they are not led or encouraged in time, it will be a blow to their self-confidence. Therefore, it should pay more attention on language teaching and better conduct bilingual education to guarantee students are able to speak mandarin or express their meaning more accurately in mandarin; meanwhile, it should respect and research the languages and literatures of minority people and find the similarities and differences as much as possible, and further it can fully utilize the positive transfer in language and culture learning and avoid negative transfer, so that it will ensure preparatory students finish cultural transition as soon as possible.

Teaching students in accordance with their aptitude requires us to arrange course contents according to their actual situation with pointed target, which involves in students' level problem. Mastery degree of Chinese, starting level of subject knowledge as well as the influence degree of regional culture and religious culture will all restrict our teaching activities, especially for language teaching and cultural teaching. And teaching at different levels by dividing national preparatory students into three levels of learning at Han-language school, learning at native-language school and experimental class have achieved initial success.

In the face of teaching objectives, it requires to improve the quality of teachers of national preparatory base and complete their knowledge structure. Some investigator thinks, there are four aspects of teachers' knowledge structure, including subject-matter knowledge, conditional knowledge, practical knowledge and cultural knowledge, of which, teachers' subject-matter knowledge refers to specific subject knowledge of them, which is the premise of preaching, teaching and dispelling doubts and is generally emphasized and strengthened in preparatory education; the conditional knowledge of teachers refers to how they preach and teach students as well as how they convert their subject-matter knowledge into students' knowledge. As for teaching of culture, it should not be taught as dry as a chip as subjectmatter knowledge, instead, we must focus on teaching methods At national preparatory stage, we must take the diversity and uniformity of nation into consideration, avoiding spoon-feed education and blindly repeating what the book says by all means. We should fully utilize the advantages of multiple minorities gathering at minority preparatory education base, completely arouse their enthusiasm, encourage them to communicate and introduce actively, make them express their own opinions in same classroom, promote them understand, respect and unify each other, and at the same time, the teacher should lead and encourage students in proper ways.

The teachers' practical knowledge and cultural knowledge play an important role at national preparatory stage. Practical knowledge refers to that teachers are able to make complex explanation and decision under uncertain teaching condition and take effective actions, and it embodies their mobility and flexibility and has a significance in teaching at different levels. Teachers' cultural knowledge has a great influence on students' cultural view and national view.

\section{CONCLUSION}

Mr. Fei Xiaotong once reduced the pattern of Chinese nation to unity in diversity, while since Chinese nation has a multi-national culture system integrated with 56 national culture systems, it determines that we must conduct multi- 
culture education at minority preparatory stage; meanwhile, aiming at the particularity of minority students at preparatory stage, we should fully take their cultural environment into consideration, effectively lead them in proper ways, so as to ensure that they are able to improve their cultural selfconsciousness and complete cultural transition when they accept the dominant culture and conduct selection of culture.

\section{REFERENCES}

[1] Liu Xiaochun. Investigation and Thoughts on Traditional Cultural Education of Current Universities and Colleges [U]. Party Construction and Ideological Education of School, 2004(10)

[2] Tong Jingju. Discussion on the Five Contradictions in Cultural Education Perplexity of Contemporary College Students [J]. Heilongjiang Researches on Higher Education, 2007, (5): 67 